\title{
Knowledge, attitudes and practices of medical researchers toward authorship in scientific journals
}

\author{
Balaji D. More', Anju B. More ${ }^{2 *}$, Harsh J. Suthar ${ }^{3}$ \\ ${ }^{1}$ Department of Pharmacology, Pacific Institute of Medical Sciences, Udaipur, Rajasthan, India \\ ${ }^{2}$ Department of Anatomy, Pacific Institute of Medical Sciences, Udaipur, Rajasthan, India \\ ${ }^{3}$ Pacific Institute of Medical Sciences, Udaipur, Rajasthan, India
}

Received: 13 January 2020

Revised: 13 February 2020

Accepted: 15 February 2020

*Correspondence:

Dr. Anju B. More,

Email: as.anju@yahoo.in

Copyright: (c) the author(s), publisher and licensee Medip Academy. This is an open-access article distributed under the terms of the Creative Commons Attribution Non-Commercial License, which permits unrestricted non-commercial use, distribution, and reproduction in any medium, provided the original work is properly cited.

\section{ABSTRACT}

Background: The knowledge, attitudes and practices of scientific authorship vary across different regions. We conducted this study to understand this variation among medical researchers in India.

Methods: An anonymous web-based researcher-survey invited all faculty, researchers and PhD students at Pacific institute of Medical sciences, Udaipur, India. The study design and the questionnaire were approved by the institutional ethics committee. Basic information on study was given to obtain consent for participation. The 30 questions on authorship experience and related issues were based on the statements in International Committee of Medical Journal Editors (ICMJE) and other national and international recommendations on authorship. Participants reported their authorship experiences and answered multiple choice questionnaires.

Results: The response rate was $36.36 \%$ among the participants, who were post-graduate with up to 10 years of research experience. About $62.5 \%$ had not been appropriately acknowledged as authors at some point during their career. Contributors (authorship) and ethical peer review is perceived as the key principle of research integrity. Though, single authorship was regarded as more significant, interdisciplinary management of diseases increases number of co-authors. A platform to challenge authorship, declaration of contribution in authorship and shared responsibility of co-authors in case of fraudulent publication was majority opinion.

Conclusions: Almost 50 of the participant medical researchers had knowledge of formal authorship requirements. Majority agreed with the criteria would help in decreasing the authorship dispute in the medical research. There is need for awareness and continuous education on these criteria.

Keywords: Articles, Authorship, Medical, Publication, Research

\section{INTRODUCTION}

Authorship in scientific publishing is a relentless topic for debate. Several issues are there concerning the authorship of scientific articles, the most common being authorship perceptions, definitions and practices. Issues regarding the extent of contribution for qualifying for authorship and the order of listing authors remains unresolved. ${ }^{1}$ The International Committee of Medical Journal Editors
(ICMJE) has developed criteria to establish standardized definitions and thereby secure responsibility and accountability of authorship in medical journals. ${ }^{2}$

In addition to the drive for scientific vigour and scholarly focus, a researchers desires to receive credit for ones contributions. This credit is generally conferred by inclusion as an author of a published research paper. The reasons for significance of this form of credit include 
research funding, career advancement and credibility among scientific community. The bias in the awarding of authorship, the disagreement on contribution and the order of co-authors can lead to disputes and bitterness. To certain extent, these disputes are addressed by policies and guidelines. The ICMJE criteria have been universally adopted, but the controversies continue and failure to abide by authorship guidelines is quite frequent. The most critical, ubiquitous and contentious issue is question of authorship.

Our results indicate that authorship is an issue among medical researchers. The prevalence of incongruous authorship is very high, as evidenced in a meta-analysis of 14 surveys which showed that an average of $29 \%$ of researchers had experienced misuse of authorship. ${ }^{3}$ Incongruous authorship leading to inadequate transparency and accountability have been substantial concerns for the scientific researcher since decades. ${ }^{4}$ In the Nordic countries, disagreements on authorship are the most common causes for investigating alleged cases of scientific delinquency. ${ }^{5}$ A survey of doctoral students revealed that $11 \%$ of participants had to face unethical pressure concerning the order of authors. ${ }^{6}$

The disputes regarding the authorship continue to increase in research institutions. The importance of integrity in authorship need to be addressed. However, our knowledge of attitudes to, and practices of, authorship in among India medical researcher is limited. Therefore this survey was conducted to assess the knowledge of attitudes to, and practices of, authorship in among India medical researcher.

\section{METHODS}

We conducted an anonymous web-based survey among researchers in between the October and December 2019. We invited all faculty, researchers and $\mathrm{PhD}$ students at Pacific institute of Medical sciences, Udaipur, India by email to answer a google web-based questionnaire. The medical researchers were informed about the study through an open invitation. They consented to their participation by answering the questionnaire.

We assessed participants experience by the number of years they had conducted research and the number of publication they had authored. Participants had to respond to 30 questions on different authorship experience and issues. Most question were based on the statements from the International Committee of Medical Journal Editors (ICMJE) and other national and international recommendations on authorship. The study design and the questionnaire was approved by the institutional ethics committee.

The data were collected related to authorship from the google web-based form and converted into excel format. The data were checked and cleaned, coded utilizing nonoverlapping numerical codes. Then, it was exported to
SPSS version 20 for analysis. Descriptive statistics, like percentage, mean and standard deviation were used to present the data as sentences, graphs, tables, frequencies, percentages.

\section{RESULTS}

\section{Researcher characteristics}

Total 154 medical researchers were sent the questionnaire of which 56 authors $(36.36 \%)$ responded. The most common qualification of the respondent $(78.6 \%)$ was postgraduation. The maximum number 24 (42.9\%) of responder had 4 to 10 years of research experience, followed by $>10$ years of experience $23.2 \%$ of responders. The basic research characteristic of the participants is illustrated in Table 1.

Table 1: The research experience parameters of the participants.

\begin{tabular}{|c|c|c|}
\hline Parameters & No. of subjects & $\%$ \\
\hline \multicolumn{3}{|c|}{ Qualification of respondents } \\
\hline Undergraduate & 1 & 1.8 \\
\hline Graduate & 4 & 7.1 \\
\hline Post-graduation & 44 & 78.6 \\
\hline Super specialist & 4 & 7.1 \\
\hline $\mathrm{PhD}$ & 3 & 5.4 \\
\hline \multicolumn{3}{|c|}{ No. of years of research experience } \\
\hline 1 & 3 & 5.4 \\
\hline 2 to 3 & 9 & 16.1 \\
\hline 4 to 10 & 24 & 42.9 \\
\hline More than 10 & 13 & 23.2 \\
\hline $\begin{array}{l}\text { Just observation and } \\
\text { analysis in medical field }\end{array}$ & 1 & 1.8 \\
\hline No research done & 3 & 5.4 \\
\hline Not answered & 3 & 5.4 \\
\hline \multicolumn{3}{|c|}{ Have you ever authored any scientific publication? } \\
\hline No & 14 & 25.0 \\
\hline Yes & 42 & 75.0 \\
\hline \multicolumn{3}{|c|}{ Total number of your publication as author } \\
\hline 1 & 4 & 7.1 \\
\hline $2-3$ & 10 & 17.9 \\
\hline $4-10$ & 20 & 35.7 \\
\hline More than 10 & 11 & 19.6 \\
\hline None & 11 & 19.6 \\
\hline \multicolumn{3}{|c|}{$\begin{array}{l}\text { Have your been not appropriately acknowledged as } \\
\text { authors at some point during their career }\end{array}$} \\
\hline No & 35 & 62.5 \\
\hline Yes & 18 & 32.1 \\
\hline No response & 3 & 5.4 \\
\hline \multicolumn{3}{|c|}{$\begin{array}{l}\text { Have you been in a dispute with a colleague over } \\
\text { authorship issues }\end{array}$} \\
\hline No & 41 & 73.2 \\
\hline Yes & 13 & 23.2 \\
\hline No response & 2 & 3.6 \\
\hline
\end{tabular}

Of the $75 \%$ responders who authored a scientific publication, majority $(35.7 \%)$ had 4 to 10 publications. 
Most responders $62.5 \%$ of were not appropriately acknowledged as authors at some point during their career. About $19.6 \%$ of responders had more than 10 publications.
The research experience characteristics (parameters) of the participants are summarised in Table 1.

Table 2: Responses of participants on knowledge regarding authorship of research publication.

\begin{tabular}{|c|c|c|}
\hline & & $\%$ \\
\hline \multicolumn{3}{|c|}{ Authorship is an important motivating factor in working and publishing collaboratively } \\
\hline No & 4 & 7.1 \\
\hline Yes & 42 & 75.9 \\
\hline Maybe & 10 & 18.5 \\
\hline No response & 4 & 7.1 \\
\hline \multicolumn{3}{|l|}{ Authorship credit should be based on } \\
\hline Drafting the article or revising it critically for important intellectual content & 1 & 1.8 \\
\hline $\begin{array}{l}\text { Substantial contributions to conception and design, acquisition of data, or analysis and } \\
\text { interpretation of data; }\end{array}$ & 8 & 14.3 \\
\hline All of the above $a$ and $b$ & 44 & 78.6 \\
\hline No response & 3 & 5.4 \\
\hline \multicolumn{3}{|c|}{$\begin{array}{l}\text { Busy and extremely time conscious researchers often do the entire clinical/laboratory work and give the data } \\
\text { and background material to a group of professional writers who will prepare the manuscript. Is this fair and } \\
\text { ethical? }\end{array}$} \\
\hline No & 38 & 67.9 \\
\hline Yes & 15 & 26.8 \\
\hline No response & 3 & 5.4 \\
\hline \multicolumn{3}{|l|}{ To be legitimately designated as an author } \\
\hline One must have participated in research & 5 & 8.9 \\
\hline Produce data whenever required & 1 & 1.8 \\
\hline Writing of the manuscript, assume public responsibility & 1 & 1.8 \\
\hline All of the above & 47 & 83.9 \\
\hline No response & 2 & 3.6 \\
\hline \multicolumn{3}{|l|}{ Good research and publication ethics condemn } \\
\hline Gift authorship & 6 & 10.7 \\
\hline Guest authorship & 2 & 3.6 \\
\hline None of the above & 10 & 17.9 \\
\hline All of above & 36 & 64.3 \\
\hline No response & 2 & 3.6 \\
\hline \multicolumn{3}{|l|}{ Which is the most common reason for guest or gift authorship? } \\
\hline Gift authorship & 4 & 7.1 \\
\hline Guest authorship & 5 & 8.9 \\
\hline All of above & 41 & 73.2 \\
\hline None of the above & 4 & 7.1 \\
\hline No response & 2 & 3.6 \\
\hline
\end{tabular}

The failure to identify as an author, someone who made substantial contributions to the research or writing of a manuscript that merited authorship, or an unnamed individual who participated in writing the manuscript is

$\begin{array}{llll}\text { Ghost authorship } & 23 & 41.1 \\ \text { Gift authorship } & 7 & 12.5 \\ \text { Guest authorship } & 5 & 8.9 \\ \text { None of the above } & 18 & 32.1 \\ \text { No response } & 3 & 5.4\end{array}$

Are you aware about criteria for authorship, as delineated in the guidelines by the International Committee of Medical Journal Editors (ICMJE)?

No

$25 \quad 44.6$

$\begin{array}{lll}\text { Yes } & 29 & 51.8\end{array}$

No response

The key principles of research integrity are

Appropriate acknowledgement of contributors (authorship) $\quad 3 \quad 5.4$

$\begin{array}{lll}\text { Both } \mathrm{a} \text { and } \mathrm{b} & 46 & 42.1\end{array}$

Don't know $\quad 2 \quad 3.6$

No response $\quad 2 \quad 3.6$




\section{Knowledge}

Authorship is an important motivator to work and publish collaboratively for $75.9 \%$ of responders. About $51.8 \%$ responders were aware of criteria for authorship delineated in the International Committee of Medical Journal Editors (ICMJE) guidelines. Almost 82.5\% responders consider appropriate acknowledgement of contributors (authorship) and ethical peer review as the key principles of research integrity.

Almost $83.9 \%$ of respondents agree that an author who participated in research and writing of the manuscript, can produce data whenever required, and assume public responsibility is legitimate. Only $41.5 \%$ responders were aware of ghost authorship. A ghost author is an unnamed individual who participated in writing the manuscript or made substantial contribution to it. The responses of participants on knowledge regarding authorship of research publication are summarized in Table 2.
In the opinion of $75 \%$ of the responders all the co-authors should be penalized in case the publication is found to be fraudulent. A corresponding author is well recognized as per $39(69.6 \%)$ of participant whereas $12(2.4 \%)$ consider the first author is the most renowned. About $69.6 \%$ of participant disagree that single author papers highlighting original research published in prestigious peer-reviewed journal assume an important role whereas $64.3 \%$ agree that critical reviews, case reports, being a co-author of a large multi-author paper assume lesser significance. Interdisciplinary approach in required in management of large number of diseases, leading to multiple authorship as per $46.4 \%$ participants whereas 42.9 held ethical issues and limited number of patients responsible for it. Almost $85.7 \%$ need platform to challenge authorship with role of each co-author clearly described in the publication. About $57.1 \%$ agree on target set of research publication for academic promotions. The responder's attitude and practice on authorship of research publications is summarised in Table 3.

\section{Attitude and practice}

Table 3: Responders attitude and practice on authorship of research publications.

\begin{tabular}{|c|c|c|}
\hline & No. & $\%$ \\
\hline \multicolumn{3}{|c|}{ Have you ever received gift or guest authorship } \\
\hline No & 48 & 85.7 \\
\hline Yes & 6 & 10.7 \\
\hline No response & 2 & 3.6 \\
\hline \multicolumn{3}{|c|}{ Have you ever been given ghost authorship? } \\
\hline No & 46 & 82.1 \\
\hline Yes & 8 & 14.3 \\
\hline No response & 2 & 3.6 \\
\hline \multicolumn{3}{|c|}{$\begin{array}{l}\text { The culture of 'publish or perish' could be the main contributor to unethical practices of authorship because } \\
\text { publication records are the main criteria for researcher's career evaluation besides, others, which are set by the } \\
\text { university. }\end{array}$} \\
\hline Agree & 45 & 80.4 \\
\hline Disagree & 8 & 14.3 \\
\hline No response & 3 & 5.4 \\
\hline \multicolumn{3}{|c|}{ Should all the co-authors penalized in case the publication is found to be fraudulent? } \\
\hline No & 12 & 21.4 \\
\hline Yes & 42 & 75.0 \\
\hline No response & 2 & 3.6 \\
\hline \multicolumn{3}{|c|}{ Which position of author in the list seems to be well recognized in medical journals? } \\
\hline Corresponding author & 12 & 21.4 \\
\hline First & 39 & 69.6 \\
\hline Second & 1 & 1.8 \\
\hline Last & 2 & 3.6 \\
\hline No response & 2 & 3.6 \\
\hline \multicolumn{3}{|c|}{$\begin{array}{l}\text { Single author papers highlighting original research published in prestigious peer-reviewed journal assume an } \\
\text { important role }\end{array}$} \\
\hline Agree & 37 & 21.4 \\
\hline Disagree & 16 & 69.6 \\
\hline No response & 3 & 5.4 \\
\hline \multicolumn{3}{|c|}{ Critical reviews, case reports, being a co-author of a large multi-author paper assume lesser significance } \\
\hline Agree & 36 & 64.3 \\
\hline Disagree & 17 & 30.4 \\
\hline
\end{tabular}




\begin{tabular}{|c|c|c|}
\hline & No. & $\%$ \\
\hline No response & 3 & 5.4 \\
\hline \multicolumn{3}{|l|}{ Why medical journals have more than one author? } \\
\hline Ethical issues & 3 & 5.4 \\
\hline Interdisciplinary approach in required in management of large number of diseases & 26 & 46.4 \\
\hline Limited number of patients & 2 & 3.6 \\
\hline All of the above & 24 & 42.9 \\
\hline No response & 1 & 1.8 \\
\hline \multicolumn{3}{|l|}{ Should there be a target set of research publication for academic promotions? } \\
\hline No & 22 & 39.3 \\
\hline Yes & 32 & 57.1 \\
\hline No response & 2 & 3.6 \\
\hline \multicolumn{3}{|l|}{ Should there be a limit on number of authors for a publication? } \\
\hline No & 21 & 37.5 \\
\hline Yes & 33 & 58.9 \\
\hline No response & 2 & 3.6 \\
\hline \multicolumn{3}{|l|}{ Should the role of each co-author be clearly described in the publication? } \\
\hline No & 7 & 12.5 \\
\hline Yes & 48 & 85.7 \\
\hline No response & 1 & 1.8 \\
\hline \multicolumn{3}{|l|}{ Should there be a platform to challenge authorship? } \\
\hline No & 6 & 10.7 \\
\hline Yes & 48 & 85.7 \\
\hline No response & 2 & 3.6 \\
\hline
\end{tabular}

A gift or guest authorship was offered to $10.7 \%$ study participants whereas $14.35 \%$ had been ghost author. Almost $80.4 \%$ of the participants agree that the culture of 'publish or perish' could be the main contributor to unethical practices of authorship. The publication records are the main measure for researcher's career evaluation over criterion set by the university. The authorship credit should be based on drafting the article or revising it critically for important intellectual content and substantial contributions to conception and design, acquisition of data, or analysis and interpretation of data according to $78.6 \%$ respondents. As per $67.9 \%$ respondents, it is fair and ethical for the busy and extremely time conscious researchers to do the entire clinical/laboratory work and give the data and background material to a group of professional writers who will prepare the manuscript. However, 64.3\% responders condemn gift authorship and guest authorship as per good research and publication ethics.

\section{DISCUSSION}

Inappropriate authorship include individuals not fulfilling the authorship criteria, have not contributed substantially in the research, unable to take public responsibility for the work, honorary authors, and ghost authors. On the contrary there are researcher who are not named as authors in spite of made significant contributions to the research published. ${ }^{2,7-9}$

The web-based survey method used in our study helps to reach out large study population cost effectively. But in spite of large study population, response rate is generally low when electronic media is applied. Present study response rate of $36.36 \%$ was in congruence with earlier studies. ${ }^{10,11}$ Compared to Nylenna et al when all potential respondents are taken into account the response rate in present study was low at $24 \% .^{10}$ Web surveys have lower response rate as compared to traditional direct paper based or mail surveys, as evident in the meta-analysis. In mail versus web-surveys, 16 of the 39 studies (44\%) had a lower response rate than current study. ${ }^{11}$

Our two third study participants were post-graduate and almost $50 \%$ more than 4 years of research experience. Almost $75 \%$ had authored a scientific publication with $35.7 \%$ having 4 to 10 publications. Unfortunately most responders $62.5 \%$ of were not appropriately acknowledged as authors at some point during their career. In the study by Nylenna et al one out of three believed that they had been excluded from deserved authorship and more than one third had experienced pressure to include undeserved authors in their papers. ${ }^{10}$ Similarly one-third Reinisch et al study participants reported that they had not been appropriately acknowledged as authors at some point during their career. ${ }^{12}$

The International Committee of Medical Journal Editors (ICMJE) document on 'uniform requirements' provides guidelines on publication of research results. ${ }^{2}$ It specifies that authorship credit should be based on (a) substantial contributions to conception and design, or acquisition of data, or analysis and interpretation of data; (b) drafting the article or revising it critically for important intellectual content; and (c) final approval of the version to be published. An author should meet all 3 conditions. The 
document further clarifies that acquisition of funding, collection of data, or general supervision of the research group, alone, does not justify authorship. All persons designated as authors should qualify for authorship, and all those who qualify should be listed. Each author should have participated sufficiently in the work to take public responsibility for appropriate portions of the content. Almost half the responders in our study were aware of 'ICMJE Criteria for authorship', though awareness is lower than the other studies. ${ }^{10}$

About $10.7 \%$ of our study participants have received gift or guest authorship. Ghost authorship was entitled to about 14.35 of the responders. Present findings are in line with the earlier research that has documented prevalence of honorary and ghost authors of $19 \%$ and $11 \%$, respectively, in articles published in biomedical journals. In review articles published by the Cochrane Library, prevalence of honorary and ghost authors was of $39 \%$ and $9 \%$, respectively..$^{13,14}$

Though, an author should pen the manuscript, $67.9 \%$ respondents thought it was fair and ethical to hire a writer. The busy and extremely time conscious researchers would do the entire clinical/laboratory work and manuscript will be prepared by professional writers based on the data and background. However, almost $83.9 \%$ of respondents consider that a legitimate author must participate in research, produce data. The responsibility of a researcher also extends to writing manuscript and assume public responsibility for it. Similarly, $64.3 \%$ responders understand that, good research and publication ethics condemn gift authorship and guest authorship.

Authorship is an important motivating factor in working and publishing collaboratively for $75.9 \%$ of responders. According to $78.6 \%$ respondents authorship credit should be based on drafting the article or revising it critically for important intellectual content and substantial contributions to conception and design, acquisition of data, or analysis and interpretation of data. Few survey questions were based on ICMJE Jan 2013 statements on Uniform Requirements for Manuscripts Submitted to Biomedical Journals. $^{2}$ The recommendations were renamed as "Recommendations for the Conduct, Reporting, Editing, and Publication of Scholarly work in Medical Journals. ${ }^{2}$ The most important addition was a new authorship criterion that emphasize each author's responsibility to stand by the integrity of the entire work and reads: "Agreement to be accountable for all aspects of the work in ensuring that questions related to the accuracy or integrity of any part of the work are appropriately investigated and resolved." About $51.8 \%$ of the responders were aware of these ICMJE guidelines, similar to other Indian study. ${ }^{15}$ Recent studies have higher percentage of awareness than older studies, suggesting that knowledge of formal authorship criteria among researchers has improved over the last 2 decades. ${ }^{16,17}$
It is well acknowledged that medical practitioner's practical approach does not always echo the principles and standards they abide by. ${ }^{18}$ This is highly relevant when it comes to scientific authorship. Despite the fact that researchers are familiar with formal authorship requirements, and even regarded breaches of these as ethically unacceptable, a large number of authors have experienced such disappointment. They have been or will be involved in disagreements on authorship. As more papers are published, wider authorship disputes are expected. In this study only $41.5 \%$ responders were aware that the failure to identify as an author is labelled as ghost authorship. An unnamed individual who made substantial contributions (that merited authorship) to the research or writing of a manuscript is referred to as ghost author. Almost $82.5 \%$ responders consider appropriate acknowledgement of contributors (authorship) and ethical peer review as the key principles of research integrity.

In ideal situation, each manuscript should bear a complete disclosure statement about the contribution for authorship. It may be achieved through continuous education or if demanded by the publisher (such as BMC Medical Ethics). ${ }^{8}$ All contributors to a study need not be awarded authorship, but should be acknowledged. ${ }^{10}$ In this regard, complete replacement of the current concept of authorship with specified contributions was not perceived well. ${ }^{8}$ So, now each co-author is assigned a numerical value to indicate relative contribution. This method would be helpful to evaluate research productivity. ${ }^{19}$ In recent times "publish or perish" is an dictum indicating the pressure to publish academic research in order to succeed. ${ }^{20}$ To encourage research and growth in the medical field, Medical Council of India have made publications mandatory for promotion. Unfortunately the pressure to publish has been cited as a reason of poor quality of research and dishonesty in authorship in academic journals. Almost $80.4 \%$ blame this regulation for unethical practices of authorship because publication records are the main criteria for researcher's career evaluation besides, others, which are set by the university.

The increasing trend of multi authored research articles papers across scientific disciplines makes the issue of the sequence of contributors' names a major topic both in terms of reflecting actual contributions and can be a reason for dispute. In this study maximum number $(39,69.6 \%)$ of participant consider corresponding author seem to be well recognized in medical journals whereas $12(2.4 \%)$ consider the first author is the most recognized. Traditionally, the first author contributes most and also receives most of the credit, whereas the position of subsequent authors is usually decided by contribution, alphabetical order, or reverse seniority. Ranking the first or second author in a two-author paper is straightforward, but the meaning of position becomes increasingly arbitrary as the number of authors increases beyond two. The guidelines to determine credit associated with the sequence of authors' names need to be evolved. ${ }^{21}$ 
Multidisciplinary and community-academic partnerships provide fertile ground for research and publications. The reason for multiple authors is stated as interdisciplinary approach required for managing large number of diseases by $46.4 \%$ participant whereas $42.9 \%$ consider ethical issues and limited number of patients responsible. About 69.6\% participant disagree that single author papers highlighting original research published in prestigious peer-reviewed journal assume an important role where as $64.3 \%$ agree that critical reviews, case reports, being a coauthor of a large multi-author paper assume lesser significance. $^{22}$

Almost $85.7 \%$ care for a platform to challenge authorship and equal percentage consider that the role of each coauthor be clearly described in the publication. The Committee on Publication Ethics (COPE), lays down the guidance for corrective measures that could be called upon by a journal in case violations of research integrity are brought to light post-publication, depending on the degree of misconduct in question. Corrective measures include either an outright retraction from the published literature of the article, an expression of concern by the journal, or a correction of the published paper issued by the journal. ${ }^{23}$ In the opinion of $75 \%$ of the responders all the co-authors should be penalized in case of fraudulent publication. To check on these, about $57.1 \%$ of responder considered that there be a target set of research publication for academic promotions.

To determine authorship and avoid conflict during research, specific task should be assigned at initial stage of project. $^{24}$ It helps to arrive at authorship decision. The dynamic process of authorship needs transparency among involved researchers. Organizations and institutions may regulate the authorship issue but this topic is seldom covered under training for responsible conduct of research. ${ }^{25}$ In addition to researchers, the institutions, editors and publishers also must understand the importance of fair crediting. Their measures may ensure adherence to current guidelines. ${ }^{26}$ However, intervention study among medical students on formal authorship criteria did not resolve the authorship dilemmas. ${ }^{27}$ Like most other research area, medical filed too fall short of informing and implementing general authorship rules. Policy statements on institutions' websites will require cultural change as authorship is a moral judgement. ${ }^{27}$ It may be accomplished with interactive lessons, "live-practice", short seminars and working groups. ${ }^{27}$

\section{CONCLUSION}

All study participants were familiar with formal authorship requirements. All agreed that any breaches of these were ethically unacceptable. Nevertheless, a high proportion had experienced such breaches. Majority of them agree with the formal authorship criteria, though it is difficult to apply in practice.

\section{ACKNOWLEDGEMENTS}

Authors acknowledge study participants for their enthusiasm and their institution for infrastructural support.

Funding: No funding sources

Conflict of interest: None declared

Ethical approval: The study was approved by the Institutional Ethics Committee

\section{REFERENCES}

1. Wager E. Recognition, reward and responsibility: why the authorship of scientific papers matters. Maturitas. 2009;62(2):109-12.

2. Rosenberg J, Bauchner H, Backus J, De Leeuw P, Drazen J, Frizelle F, et al. The New ICMJE Recommendations. Nat Med J India. 2013;26(5):2589.

3. Marušić A, Bošnjak L, Jerončić A. A systematic review of research on the meaning, ethics and practices of authorship across scholarly disciplines. PloS one. 2011;6(9):e23477.

4. Rennie D, Flanagin A. Authorship! Authorship! Guests, ghosts, grafters, and the two-sided coin. JAMA. 1994;271(6):469-71.

5. Nylenna M, Andersen D, Dahlquist G, Sarvas M, Aakvaag A. Handling of scientific dishonesty in the Nordic countries. Lancet. 1999;354(9172):57-61.

6. Hofmann B, Myhr AI, Holm S. Scientific dishonestya nationwide survey of doctoral students in Norway. BMC Med Ethics. 2013;14(1):3.

7. Smilowitz NR, Ferguson JJ, Weisz G. Controversies surrounding authorship of manuscripts by industry employees: academic and industry perspectives. EuroIntervention. 2018;13(16):1967-74.

8. Rennie D, Yank V, Emanuel L. When authorship fails: a proposal to make contributors accountable. JAMA. 1997;278(7):579-85.

9. Wislar JS, Flanagin A, Fontanarosa PB, Deangelis CD. Honorary and ghost authorship in high impact biomedical journals: a cross sectional survey. BMJ. 2011;343:d6128.

10. Nylenna M, Fagerbakk F, Kierulf P. Authorship: attitudes and practice among Norwegian researchers. BMC Med Ethics. 2014;15:53.

11. Shih TH, Fan X. Comparing response rates from web and mail surveys: A meta-analysis. Field Methods. 2008;20(3):249-71.

12. Reinisch JF, Li WY, Yu DC, Walker JW. Authorship conflicts: a study of awareness of authorship criteria among academic plastic surgeons. Plast Reconstr Surg. 2013;132(2):303e-10e.

13. Flanagin A, Carey LA, Fontanarosa PB, Phillips SG, Pace BP, Lundberg GD, et al. Prevalence of articles with honorary authors and ghost authors in peerreviewed medical journals. JAMA. 1998;280(3):2224.

14. Mowatt G, Shirran L, Grimshaw JM, Rennie D, Flanagin A, Yank V, et al. Prevalence of honorary and ghost authorship in Cochrane reviews. JAMA. 2002;287(21):2769-71. 
15. Dhaliwal U, Singh N, Bhatia A. Awareness of authorship criteria and conflict: survey in a medical institution in India. Medscape Gen Med. 2006;8(4):52.

16. Bhopal R, Rankin J, McColl E, Thomas L, Kaner E, Stacy $\mathrm{R}$, et al. The vexed question of authorship: views of researchers in a British medical faculty. BMJ. 1997;314(7086):1009-12.

17. Schroter S, Roberts J, Loder E, Penzien DB, Mahadeo S, Houle TT. Biomedical authors' awareness of publication ethics: an international survey. BMJ Open. 2018;8(11):e021282.

18. Campbell EG, Regan S, Gruen RL, Ferris TG, Rao SR, Cleary PD, et al. Professionalism in medicine: results of a national survey of physicians. Ann Intern Med. 2007;147(11):795-802.

19. Kovacs J. Honorary authorship epidemic in scholarly publications? How the current use of citation-based evaluative metrics make (pseudo) honorary authors from honest contributors of every multi-author article. J Med Ethics. 2013;39(8):509-12.

20. Neill US. Publish or perish, but at what cost? J Clin Invest. 2008;118(7):2368.

21. Tscharntke T, Hochberg ME, Rand TA, Resh VH, Krauss J. Author sequence and credit for contributions in multiauthored publications. PLoS Biol. 2007;5(1):e18.

22. Ahmed SM, Maurana CA, Engle JA, Uddin DE, Glaus KD. A method for assigning authorship in multiauthored publications. Fam Med. 1997;29(1):424.

23. Gasparyan AY, Ayvazyan L, Akazhanov NA, Kitas GD. Self-correction in biomedical publications and the scientific impact. Croat Med J. 2014;55(1):61-72.

24. Smith E, Williams-Jones B. Authorship and responsibility in health sciences research: a review of procedures for fairly allocating authorship in multiauthor studies. Sci Engg Ethics. 2012;18(2):199-212.

25. Macrina FL. Teaching authorship and publication practices in the biomedical and life sciences. Sci Engg Ethics. 2011;17(2):341-54.

26. Gasparyan AY, Ayvazyan L, Kitas GD. Authorship problems in scholarly journals: considerations for authors, peer reviewers and editors. Rheumatol Int. 2013;33(2):277-84.

27. Hren D, Sambunjak D, Marušić M, Marušić A. Medical students' decisions about authorship in disputable situations: intervention study. Sci Engg Ethics. 2013;19(2):641-51.

Cite this article as: More $\mathrm{BD}$, More $\mathrm{AB}$, Suthar HJ. Knowledge, attitudes and practices of medical researchers toward authorship in scientific journals. Int J Basic Clin Pharmacol 2020;9:582-9. 